\title{
THE INFLUENCE OF VARYING COMPOSITION OF SOIL SAMPLES ON WATER FLOW RATE (2MM SHARP SAND 1MM MEDIUM SAND)
}

\author{
Edeye Ejaita \\ Physics Department, Niger Delta University, Wilberforce Island \\ Amassoma, Bayelsa State Nigeria. \\ (Corresponding Author) ejaitadgreat@gmail.com \\ Ogobiri Godwin \\ Physics Department, Niger Delta University, Wilberforce Island \\ Amassoma, Bayelsa State Nigeria. \\ ogobiri20@yahoo.com
}

\begin{abstract}
Two different soil samples (sharp and medium) sand of (100\% sharp to $0 \%$ medium) and ( $0 \%$ sharp to $100 \%$ medium) sand were used for this research work and gotten from a sand dredging site at Amassoma community, Bayelsa State, Nigeria. These soil samples were heated differently in an oven to a temperature of $120^{\circ} \mathrm{c}$ to remove moisture and allowed to cool to room temperature of $30^{\circ} \mathrm{c}$. The soil samples were sieved with suitable sieves of about $1 \mathrm{~mm}$ for medium sand and $2 \mathrm{~mm}$ for sharp sand respective. Mixtures were then grouped into seven (7) groups with different percentages by weight in this order (100\% sharp to $0 \%$ medium), ( $80 \%$ sharp to $20 \%$ medium) down to ( $0 \%$ sharp to $100 \%$ medium). Each soil samples were poured into a transparent P.V.C. pipe with a sieve attached at the bottom of the pipe. $800 \mathrm{ml}$ of water was allowed to flow through these soil samples and the time of first drop was timed ( $\left.\mathrm{T}_{\mathrm{f}}\right)$, using a stop watch. Volume of water received $\left(V_{r c}\right)$ and volume of water retained $\left(V_{r d}\right)$ were determined using a measuring cylinder. Also, the average flow rate $\left(U_{\text {av }}\right)$ was obtained. The results from this experimental work shows that water flows through different soil samples at different flow rate as indicated in (fig. 1 to fig.7.). Figure 2 shows an increase in volume of water with respect to time. As the percentage of medium sand increases (thereby leading to a decrease in the pore spaces), the volume of water retained and time of first drop increased as well as shown in (fig.3 to fig.7). Figure 8 shows an Histogram indicating a marginal difference between the flow rate in the dry and wet soil samples. The marginal difference between the wet and dry curve is most significant at the percentage composition of sample ( $60 \%$ sharp and $40 \%$ medium sand).
\end{abstract}

\section{KEY WORDS}

Flow Rate, Time of first drop, Soil Sample, Porosity, 


\section{INTRODUCTION}

Soil is the top layer of the earth's crust. It is any non-cemented or weakly cemented particles formed by weathering of rocks.

Soil is also the mixture of minerals, organic matters, gases, liquids and the countless organisms that together support life on earth. Soil is a natural body known as the pedosphere and which performs four important functions. It is a medium for plant growth. It is a means of water supply, storage and purification. Soils are formed by either physical or chemical processes. Soils are made up of different combinations of sand, silt and clay particles which are classified based on the proportion of their sizes. Soil pore sizes are important when estimating the rate of fluid flow through the soil. Fluid moves through the soil pores either as a result of different in elevation or varying pressure. Therefore, the ability of pores to conduct water is controlled mainly by pore sizes, continuity and distribution of void in the soil (Amer, 2002). The physical properties of soil such as soil texture, structure, porosity, permeability and chemical properties such as soil reactions and buffering action, colloidal properties of soil particles etc. are mostly influenced by grain sizes which are important in determining the soil hydrologic quality (Adesunloye, 1989).

In order to make good use of soil water resources, it is necessary to understand the percolation mechanism of the soil water for surface soil layer to deep soil layer.

The objectives of this research include:

To determine the rate at which water can flow through the mixture of two different soil sample

$>$ The soil retentive capacity.

\section{BASIC THEORIES}

\section{Porosity}

Porosity is defined as the percentage of voids to the total volume of soil, given as:

$$
P \emptyset=\frac{\text { Volume of Pores }}{\text { Total Volume os soil }}(\%)
$$




\section{Hydraulic Conductivity}

Hydraulic conductivity is also known as the coefficient of permeability. It is the ease at which fluid passes through the fracture of soil which is also the measure of permeability of the media that is an important constant in the flow equation. Hydraulic conductivity mathematically is denoted by:

$$
K=\frac{V L}{A t h}
$$

where,

$\mathrm{K}=$ Hydraulic conductivity

$\mathrm{V}=$ Flow volume

$\mathrm{t}=$ Time taken

$A=$ Area of sample

$\mathrm{h}=$ Height of water

$\mathrm{L}=$ Height of sample

\section{Specific Yield}

This describes how much water can be drained away from the soil under gravity and how much water the soil actually holds. It can be expressed mathematically as:

$$
S_{y}=\frac{W y}{V}
$$

Where,

$\mathrm{W}_{\mathrm{y}}=$ Volume of water drained

$V=$ Bulk of volume of soil (Bear, 1973)

\section{Specific Retention}

Specific retention is the amount of water or fluid that the soil retains during flow. It is the ratio of volume of water soil retains after saturation against gravity to its own volume i.e:

$$
S_{r}=\frac{S_{v}}{v}
$$

Where,

$\mathrm{S}_{\mathrm{v}}=$ Volume of water occupied by retained water

$\mathrm{V}=$ Bulk volume of soil (Leaper and Uren, 1993)

\section{Darcy Law}

Darcy's law by Henry Darcy in 1956 stated that flow rate through porous media is proportional to the head loss and inversely proportional to the length of flow path. It is express in 
terms of the velocity of a purely viscous flow $\mathrm{V}(\mathrm{x})$ through soil for pressure differential $d(p)$ between faces of unit area and a distance $\mathrm{d}(\mathrm{x})$ apart is expressed as:

$$
Q=\frac{-K A h_{l}}{d_{l}}
$$

The flow (Q) through a section of area (A) is given as:

$$
\begin{aligned}
& Q=A V(X) \\
& Q=A K\left(\frac{d p}{d x}\right)
\end{aligned}
$$

For vertical flow, the flow rate $(\mathrm{Q})$ is expressed as:

$$
Q=K S\left(\frac{H+P}{P}\right)
$$

Where:

$\mathrm{K}=$ Coefficient of permeability of hydraulic conductivity dependent on the properties of both the fluid and porous medium.

$\mathrm{V} \quad=$ The discharge velocity
$\mathrm{H}=$ Head of water soil column

$\mathrm{P} \quad=$ Length of the soil column

$\mathrm{S}=$ Surface area (Hemanz et al, 2000)

\section{MATERIALS}

The materials used in this work include; Digital weigh balance, water, stop watch, oven (source of heat), thermometer, retort stand, measuring cylinder, beakers, transparent P.V.C pipe, sieve of $2 \mathrm{~mm}$ and sieve of $1 \mathrm{~mm}$.

\section{METHODOLOGY}

The research was carried out in the physics laboratory to investigate the rate at which water flow through the mixture of two soil samples. Two different soil samples (sharp and medium) sand were collected from a sand dredging site at Amassoma community in Wilberforce Island, Bayelsa State, Nigeria. The soil samples were taken to the laboratory and were heated in the oven to a temperature of about $120^{\circ} \mathrm{c}$ for 30 minutes and were allowed to cool to a temperature of $30^{\circ} \mathrm{c}$. The two soil samples were sieved using different sieve sizes $(2 \mathrm{~mm}$ and $1 \mathrm{~mm}$ for sharp and medium sandy soil respectively). 
Percentage by weight of the soil samples were obtained using the weigh balance and were mixed as detailed shown by the various tables (table 1 to 7 ) which give rise to seven different groups such as (A, B, C, D, E, F and G). The various grouped soil samples were poured into a transparent P.V.C. pipe with one end close with a sieve. The initial height of the grouped sample was taken for each and $800 \mathrm{ml}$ was measured with a beaker and was poured into the pipe. The time for first drop $\left(\mathrm{T}_{\mathrm{f}}\right)$ for each

group sample was taken. The time for the volume of water received at an interval of $100 \mathrm{ml}$ was noted as well, until the water stops to flow. The height of each saturated grouped sample was taken and another $800 \mathrm{ml}$ of water was allowed to flow through each saturated group sample and record was taken for the different time interval and the corresponding volume of water until it seizes to drop. The data obtained were interpreted with excel worksheet, by plotting graphs of volume of water (ml) against time (sec) using Microsoft Excel, 2013 version.

\section{RESULTS}

The results obtained from the various experiment are presented in tabular form and are graphically represented in (fig.1 to fig.7) The average flow rate $\left(U_{a v}\right)$ for both samples is also presented in tables, see details in table 8 . The average flow rates of both samples are represented graphically as shown in fig. 8

\section{Table 1: Sample A (100\% Sharp and 0\% Medium)}

\begin{tabular}{|cccc|}
\hline \multicolumn{2}{|c|}{ DRY } & \multicolumn{2}{c|}{ WET } \\
\hline Volume (ml) & Time (Sec) & Volume (ml) & Time (Sec) \\
0 & 4 & 100 & 6 \\
100 & 8 & 200 & 10 \\
200 & 11 & 300 & 14 \\
300 & 14 & 400 & 18 \\
400 & 18 & 500 & 23 \\
500 & 22 & 600 & 28 \\
600 & 27 & 700 & 35 \\
700 & 50 & 800 & 81 \\
730 & 121 & 810 & 135 \\
\hline
\end{tabular}


Table 2: Sample B (80\% Sharp and 20\% Medium)

\begin{tabular}{|cccc|}
\hline \multicolumn{2}{|c|}{ DRY } & \multicolumn{2}{c|}{ WET } \\
\hline Volume (ml) & Time (Sec) & Volume (ml) & Time (Sec) \\
0 & 5 & 100 & 8 \\
100 & 17 & 200 & 12 \\
200 & 24 & 300 & 16 \\
300 & 32 & 400 & 22 \\
400 & 42 & 500 & 28 \\
500 & 53 & 600 & 35 \\
600 & 68 & 700 & 43 \\
700 & 331 & 800 & 60 \\
720 & & 840 & 122 \\
\hline
\end{tabular}

Table 3: Sample C (60\% Sharp and 40\% Medium)

\begin{tabular}{|cccc|}
\hline \multicolumn{2}{|c|}{ DRY } & \multicolumn{2}{c|}{ WET } \\
\hline Volume (ml) & Time (Sec) & Volume (ml) & Time (Sec) \\
0 & 6 & 100 & 11 \\
100 & 13 & 200 & 19 \\
200 & 18 & 300 & 27 \\
300 & 24 & 400 & 37 \\
400 & 31 & 500 & 47 \\
500 & 40 & 600 & 59 \\
600 & 50 & 700 & 73 \\
700 & 224 & 800 & 164 \\
& & 810 & 368 \\
\hline
\end{tabular}

Table 4: Sample D (50\% Sharp and 50\% Medium)

\begin{tabular}{|cccc|}
\hline \multicolumn{2}{|c|}{ DRY } & \multicolumn{2}{c|}{ WET } \\
\hline Volume (ml) & Time (Sec) & Volume (ml) & Time (Sec) \\
0 & 7 & 100 & 13 \\
100 & 15 & 200 & 22 \\
200 & 21 & 300 & 32 \\
300 & 28 & 400 & 44 \\
400 & 37 & 500 & 56 \\
500 & 46 & 600 & 71 \\
600 & 58 & 700 & 86 \\
700 & 189 & 800 & 141 \\
& & 820 & 300 \\
\hline
\end{tabular}

Table 5: Sample E (30\% Sharp and 70\% Medium)

\begin{tabular}{|c|ccc|}
\hline DRY & \multicolumn{3}{|c|}{ WET } \\
\hline Volume (ml) & Time (Sec) & Volume (ml) & Time (Sec) \\
0 & 9 & 100 & 15 \\
100 & 16 & 200 & 25 \\
200 & 23 & 300 & 35 \\
300 & 31 & 400 & 49 \\
400 & 40 & 500 & 62 \\
500 & 50 & 600 & 80 \\
600 & 64 & 700 & 120 \\
700 & 300 & 800 & 180 \\
& & 820 & 336 \\
\hline
\end{tabular}


Table 6: Sample F (10\% Sharp and 90\% Medium)

\begin{tabular}{|cccc|}
\hline \multicolumn{2}{|c|}{ DRY } & \multicolumn{2}{c|}{ WET } \\
\hline Volume (ml) & Time (Sec) & Volume (ml) & Time (Sec) \\
0 & 9 & 100 & 14 \\
100 & 17 & 200 & 25 \\
200 & 24 & 300 & 36 \\
300 & 32 & 400 & 50 \\
400 & 42 & 500 & 64 \\
500 & 53 & 600 & 81 \\
600 & 68 & 700 & 102 \\
690 & 335 & 800 & 155 \\
& & 820 & 279 \\
\hline
\end{tabular}

Table 7: Sample G (0\% Sharp and 100\% Medium)

\begin{tabular}{|cccc|}
\hline \multicolumn{2}{|c|}{ DRY } & \multicolumn{2}{c|}{ WET } \\
\hline Volume (ml) & Time (Sec) & Volume (ml) & Time (Sec) \\
0 & 10 & 100 & 13 \\
100 & 18 & 200 & 24 \\
200 & 25 & 300 & 37 \\
300 & 34 & 400 & 50 \\
400 & 44 & 500 & 61 \\
500 & 55 & 600 & 79 \\
600 & 70 & 700 & 100 \\
690 & 277 & 800 & 150 \\
& & 820 & 270 \\
\hline
\end{tabular}

Table 8: Average Flow Rate Table

\begin{tabular}{|c|c|c|}
\hline Samples & $\begin{array}{c}\text { DRY } \\
\text { Average Flow Rate } \\
\text { (MI/S) }\end{array}$ & $\begin{array}{c}\text { WET } \\
\text { Average Flow } \\
\text { Rate(MI/S) }\end{array}$ \\
\hline A & 14 & 20 \\
B & 12.9 & 13.2 \\
C & 3.8 & 9.58 \\
D & 3.6 & 8.13 \\
E & 2.3 & 5.83 \\
F & 1.84 & 5 \\
G & 1.81 & 4.79 \\
\hline
\end{tabular}

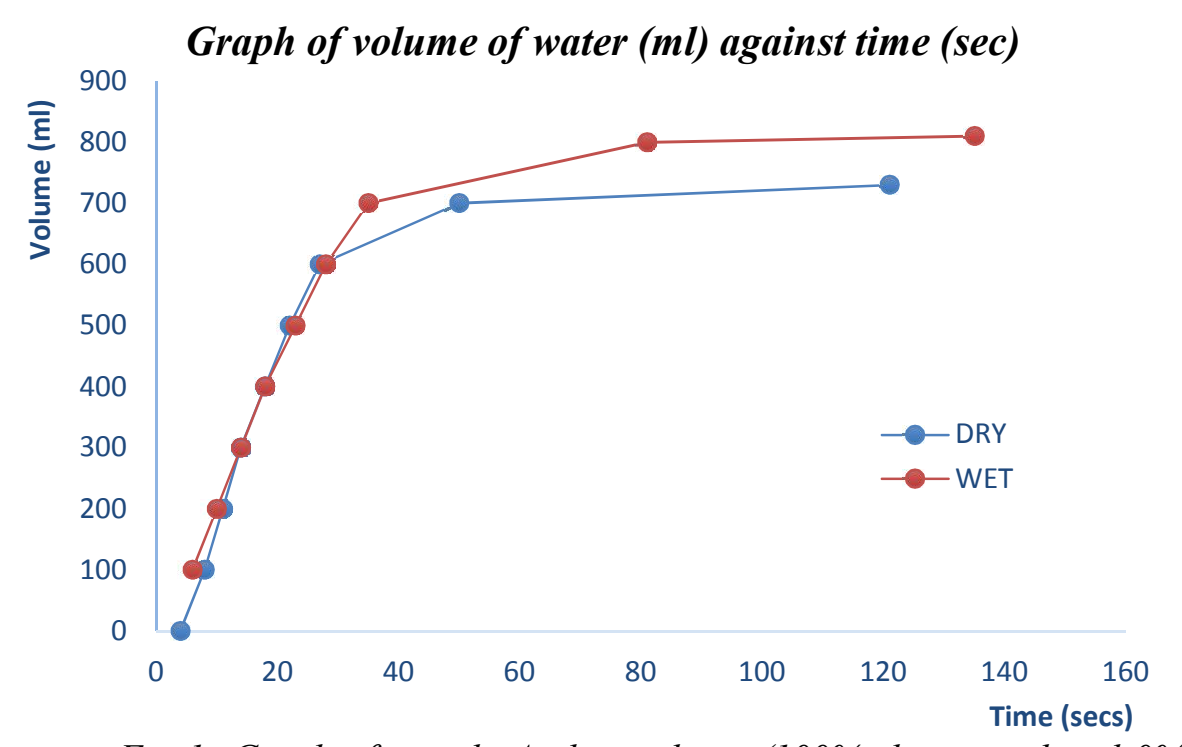

Fig 1: Graph of sample A, dry and wet (100\% sharp sand and $0 \%$ medium sand) 


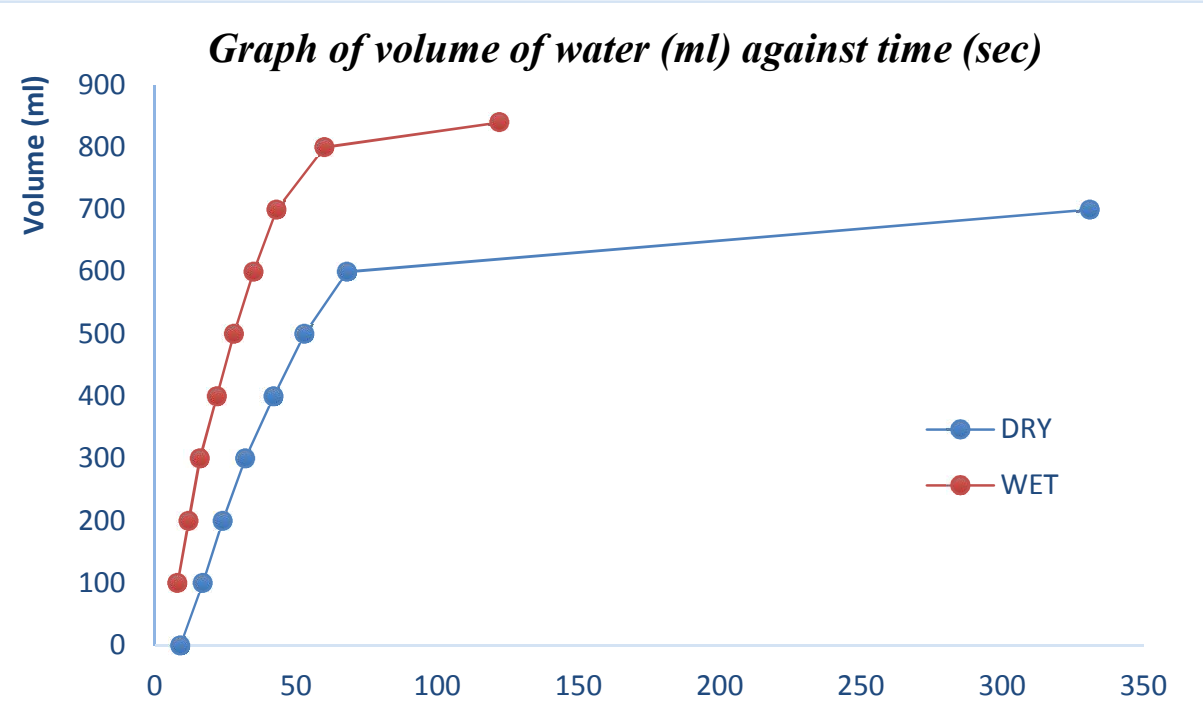

Fig 2: Graph of sample B, dry and wet (80\% sharp sand and 20\% Time (sec) medium sand)

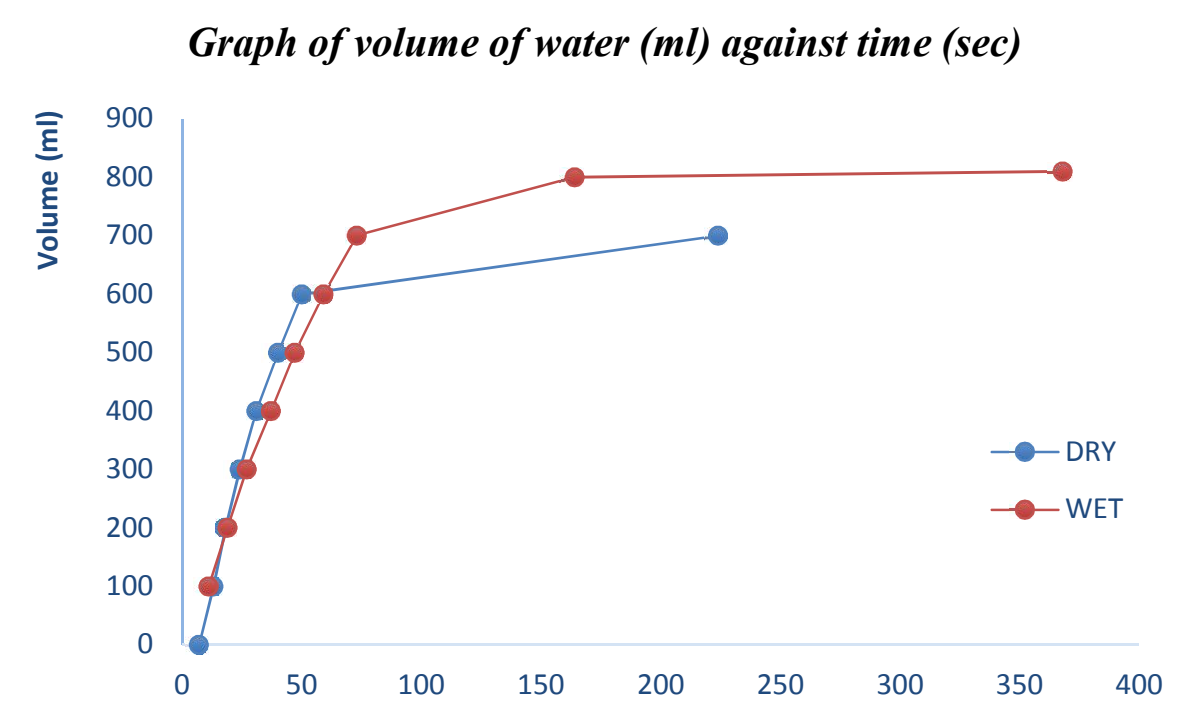

Fig 3: Graph of sample C, dry and wet (60\% sharp sand Time (sec) and $40 \%$ medium sand)

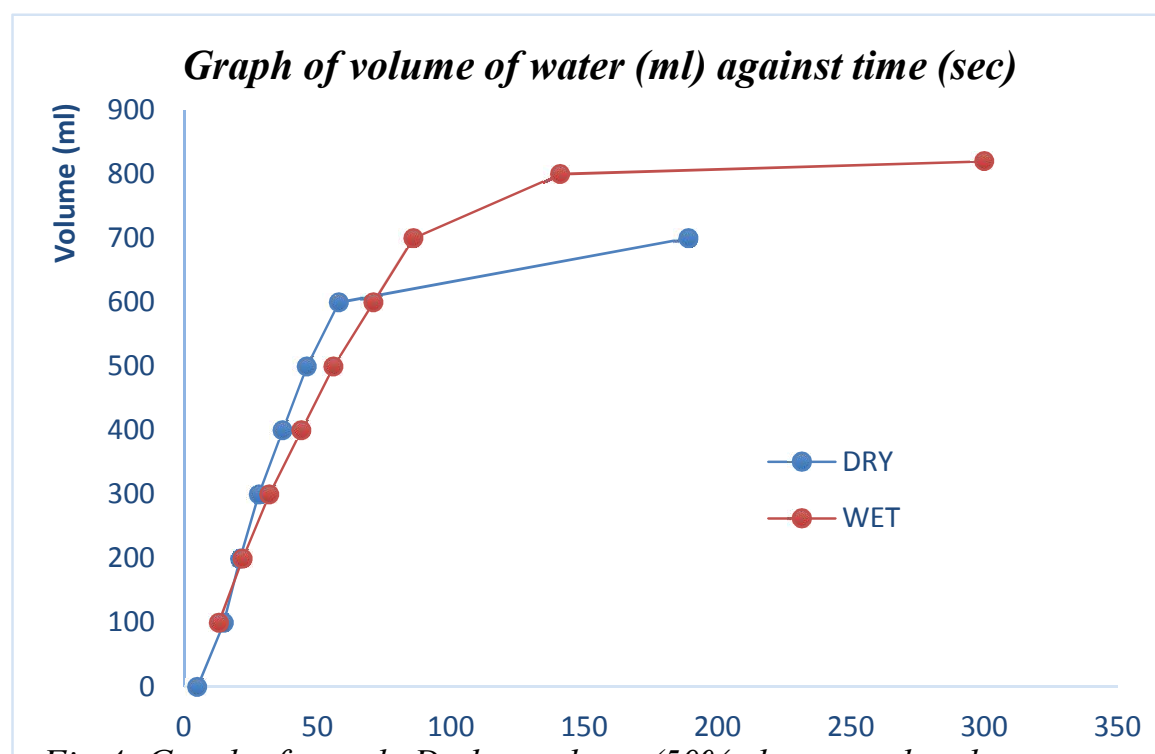

Fig 4: Graph of sample D, dry and wet (50\% sharp sand and Time (sec) $50 \%$ medium sand)

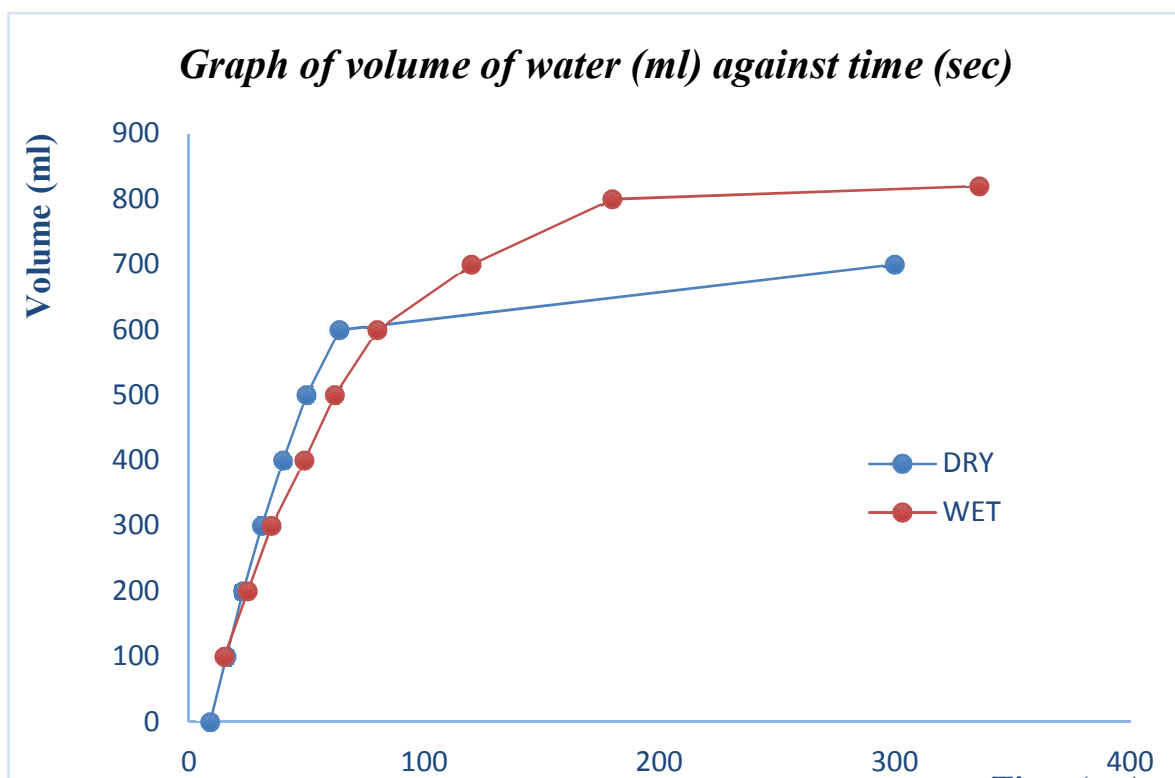

Fig 5: Graph of sample E, dry and wet (30\% sharp sand and Time (sec) $70 \%$ medium sand) 

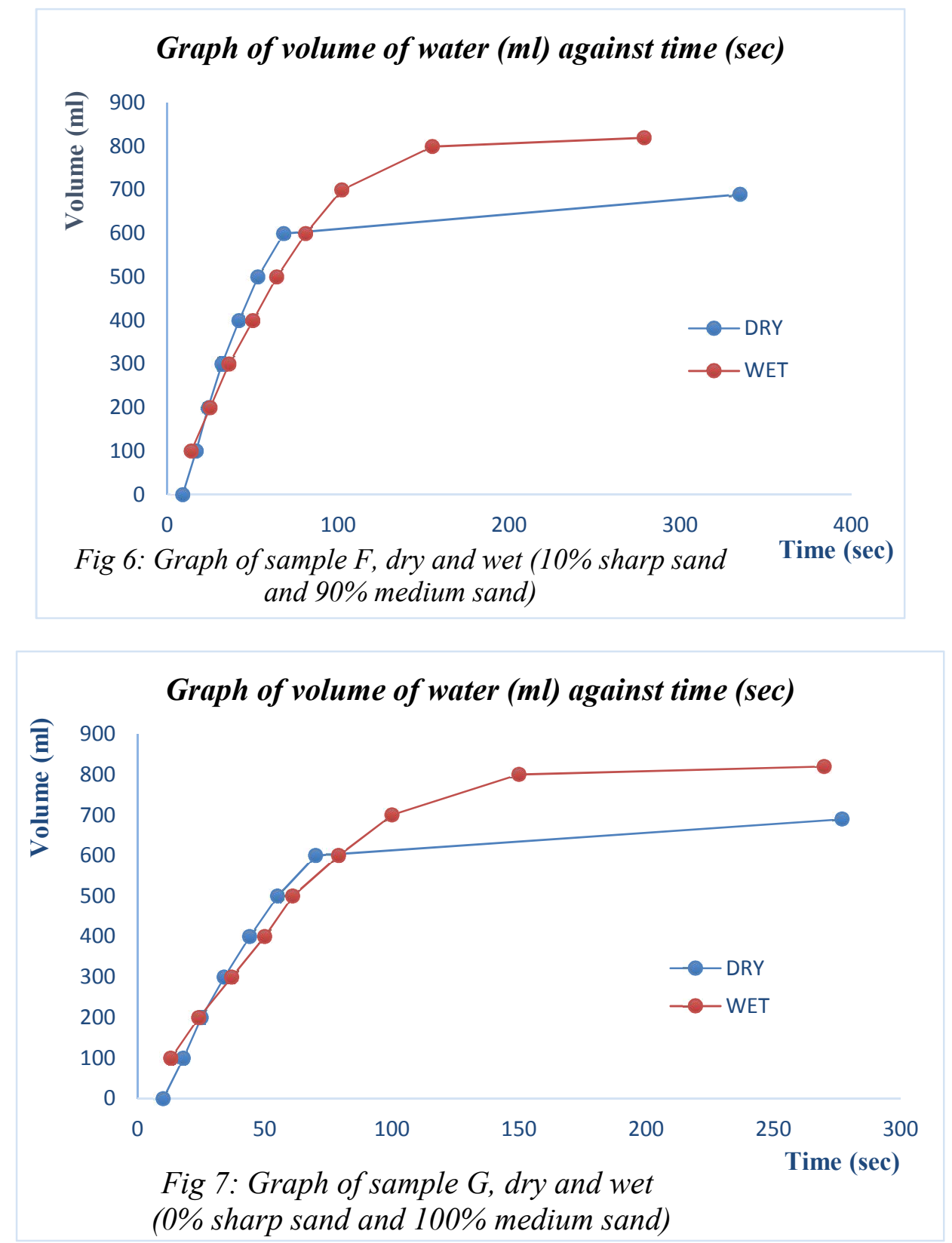

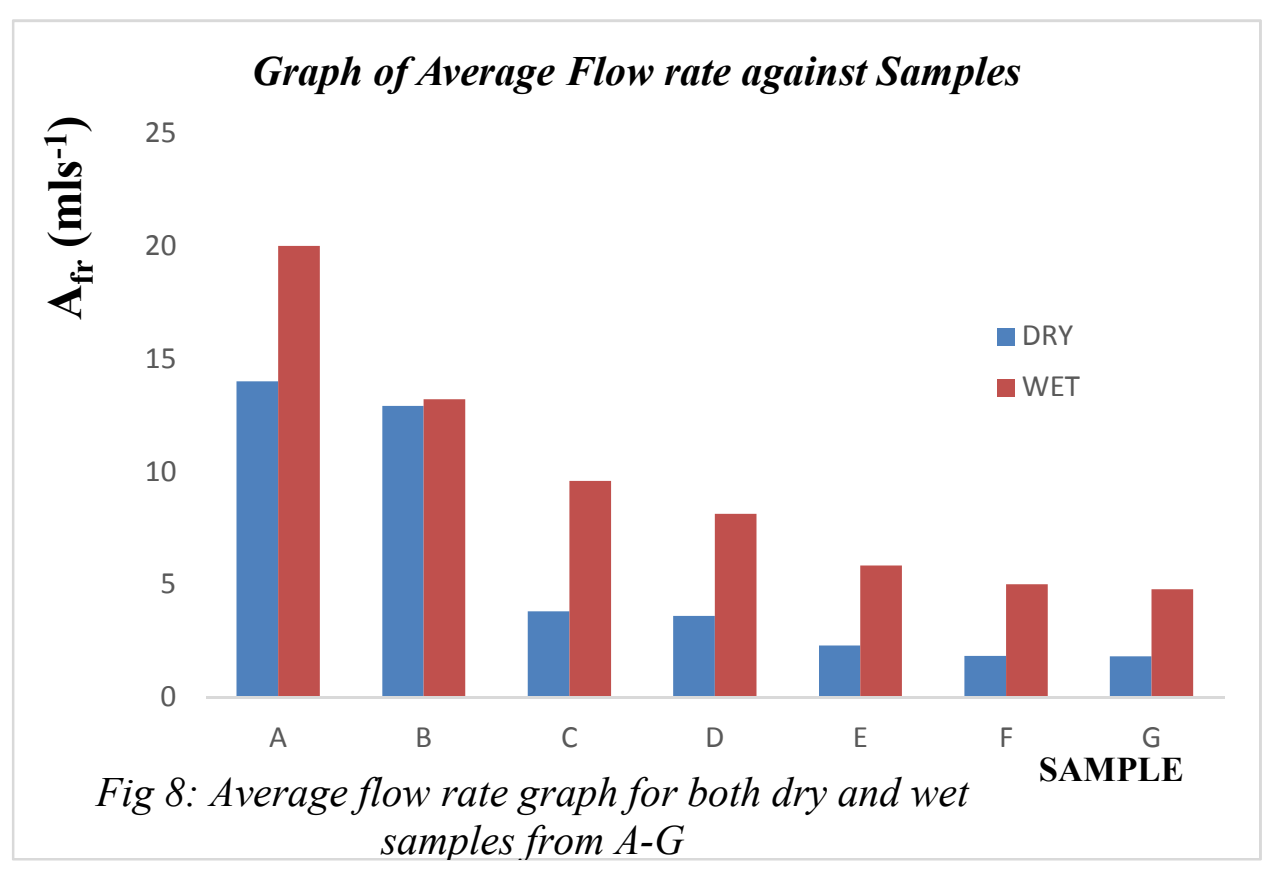

\section{DISCUSSION}

The results obtained in this work indicate that water percolated through the soil samples at different rates. Water percolation decreases gradually from sample A (100\% sharp sand and $0 \%$ medium sand) down to sample G (0\% sharp sand and 100\% medium sand) with percentage increase in medium sand. A maximum average flow rate of $14.00 \mathrm{ml} / \mathrm{s}$ was obtained for both dry and wet samples respectively for sample A and a minimum average flow rate of $1.81 \mathrm{ml} / \mathrm{s}$ and $4.79 \mathrm{ml} / \mathrm{s}$ for both dry and wet 
sample respectively for sample G. Consequently, it was observed that from fig. 8 that there is a marginal difference between the flow rate in the dry and wet sample which suggest that there is a large degree of compaction of the different mixtures. Also, the time of first drop varies for the dry samples, while that of the wet samples was at zero as observed from the graph. Consequently, the volume of water received and water retained varies for the dry and wet samples. This is due to the difference in grain size and particle arrangement. Also, for the dry sample, the soil is well disturbed than that of the wet sample. This explains why the decrease is not linear but shows minimum between the experimented sample $A$ and $G$ in sharp and medium sand. The packing arrangement reduces the voids because medium sand with relatively small size tends to occupy the void spaces between the sharp and medium sand mixture, thereby reducing the number of voids and as well as affecting the possible connectivity between voids (i.e. permeability). Consequently, with increasing medium sand in the mixture of both samples, the average flow rate decreases.

\section{CONCLUSION}

In conclusion, the graphs (fig.1 to fig.7) indicate that the flow rate for the wet sample is greater than that of the dry sample. This is due to compaction of soil particle, which influences permeability, porosity, and hydraulic conductivity of soil. The marginal difference between the wet flow curve and the dry flow curve is most significant at percentage composition of (60\% sharp sand and $40 \%$ medium) sand. It is easily acceptable to presume that this percentage composition indicates a substantial compaction and a consequent decrease in porosity. This study has guided me to separate the percentage composition that has a high rate of percolation and retentive capacity.

\section{REFERENCES}

1. Adesunloye, M.O. (1989). Investigating problem soils of Nigeria. $9^{\text {th }}$ regional conference on soil mechanisms and foundation Engineering for Africa. 1, 105-112.

2. Amer, A.M. (2002). Drainable and water filled pores as related to water storage and conductivity in agricultural 
soils of Nile Delta. Verb internal Verein, Limnology. 28(4), 1912-1919.

3. Bear, J. (1973). The dynamics of fluid in pore media.

New York: John and Sons. 567-569.

4. Frankel, H.J, Goertzan, o. and Rhoads, J.D. (1978). Effects of clay types and content and soil hydraulic conductivity. California: Standford University. 42,32-39.

5. Hermanz, J. L., Pixoto, H., Cerisola, C. and Sanchez, V.

(200). Predicting soil density soil profile in field condition sing penetration resistance, moisture content and soil depth. 93,167-184.

6. Kerman, P.J., Ritz, R.W., Dominiji, D.F and Conrad, C.M. (2007). Porosity and permeability in sediment mixtures groundwater. 45(4), 429-438.

7. Leeper, G.W. and Uren, U.C (1993). Soil Science an introduction $\left(5^{\text {th }} \mathrm{ed}\right)$. Melbourne: Oxford University press. 8. Mohanty, K.K and Salter, S.J (1982). Multiple flow in porous media, $5^{\text {th }}$ annual tech. conference Dallas 1:21 9. Mitchell, J.K (1995) fundamentals of soil behavior. New York: John and Sons. 118-120.

10. Salt, P.J., Berry, G. and Williams, J.B (1996). The influence of texture on the moisture characteristics of soils. Melbourne: Oxford University Press. 19,93-98.
11. Velde, B. (1995). Composition and mineralogy of clay minerals in Velde, origin and mineralogy of clay. New York: Springer Verlog. 8:42 